\title{
COVID-19 and the elderly: insights into pathogenesis and clinical decision-making
}

\author{
Fabio Perrotta ${ }^{1}$ (C) Graziamaria Corbi ${ }^{1,2} \cdot$ Grazia Mazzeo $^{3,4} \cdot$ Matilde Boccia $^{3} \cdot$ Luigi Aronne $^{3} \cdot$ Vito D'Agnano $^{3}$. \\ Klara Komici ${ }^{1,2} \cdot$ Gennaro Mazzarella $^{3} \cdot$ Roberto Parrella $^{5} \cdot$ Andrea Bianco $^{3,4}$
}

Received: 18 May 2020 / Accepted: 6 June 2020 / Published online: 16 June 2020

(c) Springer Nature Switzerland AG 2020

\begin{abstract}
The elderly may represent a specific cluster of high-risk patients for developing COVID-19 with rapidly progressive clinical deterioration. Indeed, in older individuals, immunosenescence and comorbid disorders are more likely to promote viralinduced cytokine storm resulting in life-threatening respiratory failure and multisystemic involvement. Early diagnosis and individualized therapeutic management should be developed for elderly subjects based on personal medical history and polypharmacotherapy. Our review examines the pathogenesis and clinical implications of ageing in COVID-19 patients; finally, we discuss the evidence and controversies in the management in the long-stay residential care homes and aspects of end-of-life care for elderly patients with COVID-19.
\end{abstract}

Keywords Sars-Cov- $2 \cdot$ Coronavirus $\cdot$ COVID-19 Elderly patients $\cdot$ Nursing homes $\cdot$ Palliation

\section{Background}

The novel coronavirus disease (COVID-19) caused by SARS-CoV-2 has spread quickly: by April 26th 2020, 193.710 deaths worldwide had been reported by World Health Organisation (WHO) and COVID-19 has emerged as a very large-scale pandemic [1]. Evidence suggests that advanced age is the most important predictor for fatal outcome [2].

Fabio Perrotta and Graziamaria Corbi equally contributed to the article.

Fabio Perrotta

fabio.perrotta@unimol.it

1 Department of Medicine and Health Sciences, "Vincenzo Tiberio", University of Molise, Via Francesco De Sanctis, 86100 Campobasso, Italy

2 Italian Society of Gerontology and Geriatrics (SIGG), Florence, Italy

3 Department of Translational Medical Sciences, University of Campania “L. Vanvitelli”/Hosp. Monaldi, 80131 Naples, Italy

4 COVID-19 Unit, Infectious Disease Department, University of Campania “L. Vanvitelli”, 80131 Naples, Italy

5 COVID Unit D, Department of Infectious Diseases, Cotugno Hospital, A.O.R.N. dei Colli, Naples, Italy
Coronaviruses represent a heterogeneous cluster of large single-strand RNA viruses, widely distributed among mammals and birds and grouped in the family of Coronaviridae [3]. The genera of interest for humans are alpha and betacoronavirus which compose the subfamily of Coronavirinae, along with gamma and delta coronavirus, not recognised as human pathogens [4]. At the end of the second decade of the twenty-first century, the world has witnessed an outbreak of a novel coronavirus, designated SARS-CoV-2, and taxonomically allocated into the species of severe acute respiratory syndrome-related coronavirus (SARS-CoV), subgenus Sarbecovirus, genus betacoronavirus [5, 6]. The term coined to refer to SARS-CoV-2-related disease is COVID-19 [7]. Droplets and close contact have been recognised as the main routes of transmission of COVID-19 virus [8], though the fecal-oral route cannot be excluded $[9,10]$.

The COVID-19 clinical scenario is far from being homogenous. Indeed it ranges from milder symptoms such as fever, dry cough, and dyspnoea to acute respiratory distress syndrome (ARDS) which may, lastly, lead to death [11-13]. Furthermore, an asymptomatic course has also been reported, making infection containment more challenging [14].

Among patients infected with SARS-CoV-2, several conditions are linked to increased virus susceptibility and elevated COVID-19 burden. As comorbidities often increase 
with aging, the elderly population may in turn experience a more severe COVID-19. Aging itself has been strongly associated with worse outcomes, because of the pathophysiological changes that characterize the respiratory system [15]. Based on current epidemiological data, SARS-CoV2-infected patients aged $>80$ show a greater risk of death in comparison with younger patients [13, 16-18].

This review explores the impact of COVID-19 in the elderly, investigating features of SARS-CoV-2 infection in these subjects, and finally discusses the strategies to face this health emergency.

\section{Methods}

The review was conducted following the Preferred Reporting Items for Systematic Reviews and Meta-Analyses (PRISMA) checklist [19] (Supplementary file). A systematic literature search was conducted by Medline, Embase, and Cochrane Database, including articles published in the last 20 years (from 2000 to 2020). Only the articles written in English were included. The following MESH terms were used: COVID-19, SARS, MERS, coronavirus, viral pneumonia, and Elderly. We, therefore, report a narrative review of the abovementioned research.

\section{SARS-CoV-2 pathogenesis: implications for older adults}

Upper airways represent the entry site for respiratory infections including SARS-CoV-2 [20-25].

Whilst most of the patients succeed in overcoming the infection, others do not and aging represents a risk factor for poor outcome. Svartengren et al. showed, in individuals aged 19-81 years, an age-related decline in the clearance of inhaled particles in the small airway region [26], suggesting this finding as one factor responsible for the high prevalence of respiratory symptoms among the elderly. The evidence of a gradual decrease in the number of cilia and ciliated cells in the airway with aging supports this hypothesis [27]. Moreover, Martin et al. [28] demonstrated that upper airway size decreases with increasing age in both men and women and that men have greater upper airway collapsibility than women. This could also represent another key-point in the explanation of the different prevalence of COVID infection by gender. Nevertheless, a progressive and relatively linear increase in nasal cavity volume with increasing age coupled with an age-dependent decrease of nasal resistance might represent determinants for a higher prevalence of COVID in the elderly population [29].

After the early stages of respiratory infection, lung involvement may potentially progress toward more severe disease which is usually associated with acute respiratory distress [30, 31]. Furthermore, COVID-19 is known to affect many different organs other than lungs, and patients may develop non-respiratory symptoms [32].

In common with other coronaviruses, SARS-CoV-2 uses its spike (S) protein, a main structural component of the viral particle, to attach to human cells. However, to achieve fusion, $S$ protein requires priming by a host protease [33, 34]. Angiotensin converting enzyme-2 (ACE2) has been found to be the SARS-CoV-2 cell entry receptor while TMPRSS2, a cellular transmembrane serine protease, is employed by the virus for $\mathrm{S}$ protein priming [35-37]. In lung cells, by cleaving a single residue from angiotensin II (AngII), ACE2 generates its product AngI-VII which, in turn, down-regulates the inflammatory effects of AngII [38-40]. Upon viral entry, the spike proteins of both SARS$\mathrm{CoV}$ and SARS-CoV-2 cause the internalization and degradation of ACE2 that critically contribute to lung damage $[41,42]$. Decrease of ACE2 activity exacerbates the severity of lung injuries and inflammatory lung diseases [42]. Type II alveolar cells are not the only ones to express ACE2: indeed, it has been detected on myocardium, kidney, urothelial, ileum, colon, esophagus, and oral mucosa cells [43]. This may in part explain the multiple systemic presentations of COVID-19. Recent evidence suggests that while younger subjects may be more prone to get infected, lower levels of ACE2 in older patients may prompt more severe clinical behavior of COVID-19 [44]. Furthermore, patients with more aggressive COVID-19 clinical behavior are more often in older age groups and may progress towards ARDS [45]. In line with the data provided by the Istituto Superiore di Sanità (ISS), ARDS was observed in the majority of patients (96.8\% of cases) dying in hospital [18]. Notably, ARDS has been found to be higher in the elderly as well as in subjects with acute heart, liver, and kidney function disorders [30, 46].

In contrast with ARDS observed during other infections, in SARS-CoV-2-infected patients, a peculiar dissociation between hypoxemia severity and relatively well-preserved pump ventilatory mechanism was reported [47]. Histological analysis performed on post-mortem lungs of COVID-19 patients is consistent with diffuse alveolar damage (DAD) [32]. Furthermore, hyaline membrane formation, vascular congestion, and large areas of intra-alveolar hemorrhages have been described. A notable finding was the presence of $\mathrm{CD} 61+$, presumably resident pulmonary megakaryocytes, within alveolar capillaries assumed to actively produce platelets [48, 49].

Inflammation emerges as a crucial process in SARS-CoV2 -infected patients. While a strong immune response may contain the infection, accumulating studies have reported worse outcomes related to the presence of an excessive number of cytokines and inflammation mediators. Leucocytosis, elevated ALT, lactate dehydrogenase, high-sensitivity 
cardiac troponin I, creatine kinase, d-dimer, prothrombin time, serum ferritin, procalcitonin, and IL- 6 have been associated with death in a cohort of 191 patients infected with SARS-CoV-2 [13]. Similarly, higher concentrations of cytokines have been reported in both ICU patients and non-ICU patients in comparison with healthy adults. Further evaluations showed that plasma concentrations of IL2, IL7, IL10, GCSF, IP10, MCP1, MIP1A, and TNF $\alpha$ were higher in ICU patients than non-ICU patients [50]. The chaotic increase of excessive cytokines produces a cytokine storm which, along with disruption of anti-inflammatory mechanisms, may prompt an imbalance in coagulative axis resulting in fatal outcomes [51-57] (Fig. 1).

\section{Aging and comorbidities increase the susceptibility to viral infection}

Immunosenescence represents a recognized feature of aging. As age advances, disruption of both innate and adaptive arms of the immune system has been reported. In addition, the elderly exhibit a continual production of inflammatory mediators and cytokines, also known as 'inflammaging' [58-60]. Furthermore, aberrant ciliary function and ciliary ultrastructural anomalies might jeopardize successful clearance of virus SARS-CoV-2 particles in older adults [61].

A complex network between innate and adaptive immune effector cells is crucial for a competent response against microbes. Via Toll-like receptors (TLRs), antigenpresenting cells (APCs) recognize the strategic segment of microbe, known as pathogen-associated molecular patterns or (PAMPs), eliciting a secretion of different cytokines and synchronizing effector cells. Both expression and downstream signalling of TLRs seem to be impaired in elderly people leading to an improper immune response $[62,63]$. However, an upregulation of TLR-4 in monocyte-derived dendritic cells appears to favor inflammation in elderly [64]. Intriguingly, an overactive immune system may explain the adverse contribution of hypertension in SARS-CoV-2 infection. TLR4 expression, the same augmented in the elderly, has been reported to be increased in hypertensive models whilst T-cell function is surprisingly depressed. Conversely, an anti-TLR4 treatment ameliorates inflammation; while, a decline in blood pressure levels is reported once T-cell function is restored [65, 66]. Viral infections, especially those responsible for chronic or latent infections, are suspected to influence T-cell functions in elderly. A negative correlation between CD4/CD8 T-cell ratio and severity of frailty in the elderly has been reported $[62,67,68]$. However, the behavior of the CD4/ CD8 ratio in COVID-19 elderly patients must be fully explored. The number of circulating 'competent' B cells has been shown to significantly decrease with age, whilst the percentage of terminally differentiated and senescent memory CD27-B cells increases in the elderly [69]. In many previous studies, the impact of this decline on the immune system responses to viral infections has been extensively investigated. Cumulative incidence of influenza virus was highly reported among children although more influenza-attributable hospitalizations were recorded in the elderly [70]. Annual vaccination against influenza is recommended for persons with comorbidities, older adults, and caregivers; nevertheless, significant mortality in people aged 65 or over is observed [71]. Though vaccines do not succeed in eradicating influenza, their positive effect, in modulating infection and preventing complications and sequelae including pneumonia, other bacterial infections, and even death, must be acknowledged [72]. Unfortunately, the effectiveness of vaccines among older people against influenza-like illness has been reported to be reduced in comparison with younger subjects, reflecting an impairment of both effector memory $\mathrm{T}$ cells and efficient B cells $[64,73,74]$. Questions upon the impact of these features on the COVID-19 course in elderly patients remain.
Fig. 1 Proposed risk factors and pathogenetic mechanisms underlying increased mortality among elderly with SARS$\mathrm{CoV}-2$ infection

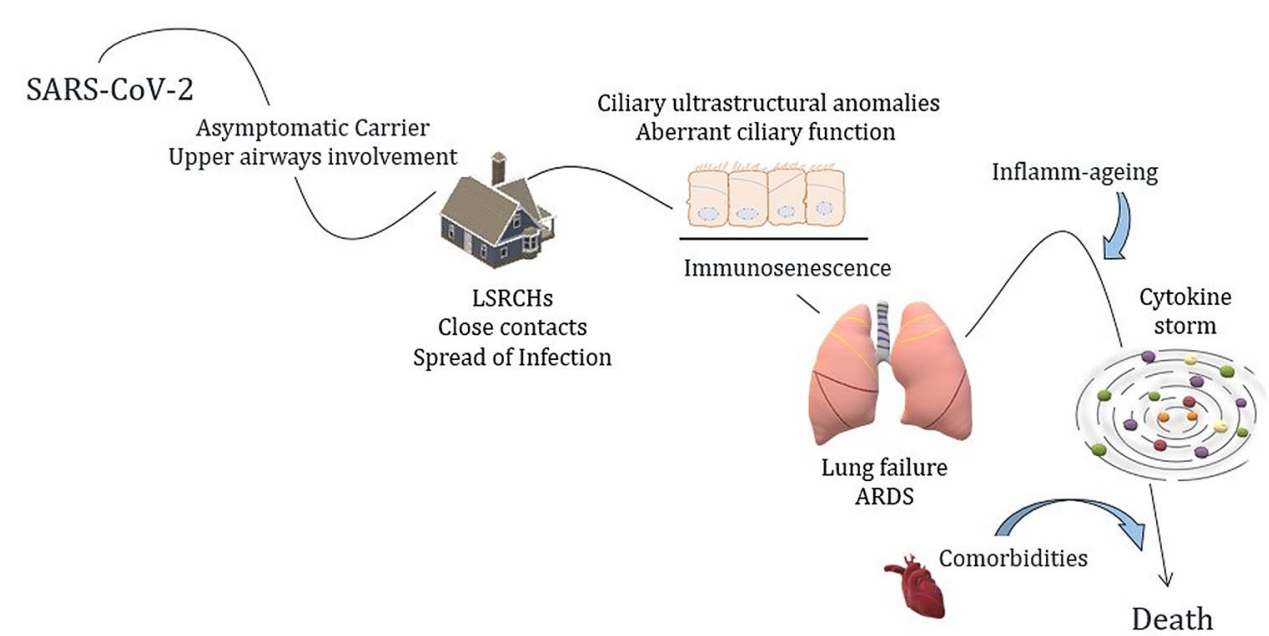




\section{Sex-related issues in elderly COVID-19 patients}

In addition to a higher susceptibility due to aging, epidemiological studies revealed sex-specific differences in the incidence and mortality in humans after SARS-CoV and SARS-CoV2 infection, with males experiencing higher mortality compared with females [75-78]. Interestingly, this sexdependent increase in disease severity after pathogenic $\mathrm{CoV}$ infection is more pronounced with advancing age $[75,77]$.

Early studies from pre-clinical models investigated about the sex-related differences in virus susceptibility and disease severity. Xie and coworkers have shown a significant reduction of ACE2 expression in old rats of both genders compared to both young adult and middle aged $(p<0.001)$. However, a relatively higher expression of ACE2 has been reported in old female rats compared to old males $(p<0.05)$, with no significant difference in ACE2 content between genders in younger groups [79].

Indeed, the ACE2 gene may be transcriptionally regulated by DNA methylation [80]. The DNA methylation of this gene results in gene repression and angiotensin converting enzyme upregulation [81].

The localization of ACE2 on the X chromosome [82] raises the possibility of gender differences in susceptibility and progression of COVID 2019 [75, 83]. In particular, the ACE2 gene could possibly experience differences in methylation due to $\mathrm{X}$ chromosome activation. Recently Fan et al. demonstrated that, in humans, sex may significantly influence different aberrant methylation of the ACE2 promoter, which might explain the increased risk of COVID-19 infection in men [84]. DNA methylation is also associated with being a potential driver of biological aging [85]. Moreover, sex chromosomes undergo differential methylation changes during the aging process compared with that on autosomal chromosomes [86].

Indeed, recently Jin et al. showed that older age is a predominant risk factor for severity and morbidity in patients with COVID-19. While males and females have the same susceptibility to COVID-19, male patients may be more prone to dying independent of age [85].

Different responses of males and females to several RNA and DNA virus infections [86] represent another compelling factor. A possible explanation of these differences might be found in a different gender-oriented immunological response. Using a mouse model of SARS-CoV infection, Channappanavar et al. showed that male mice are more susceptible to SARS-CoV infection than female mice. The enhanced susceptibility of male mice to SARS-CoV correlated with a moderate increase in virus titer and extensive inflammatory monocyte macrophages and neutrophil accumulation in the lungs [87].

Males generate less robust immune responses and are more susceptible to infectious agents [86]. In fact, aging males experience a more dramatic decrease in total numbers of $\mathrm{T}$ and $\mathrm{B}$ cells and larger increases in senescent $\mathrm{CD} 8+\mathrm{T}$ effector memory cells as compared with females [88]. Also, a larger proportion of elderly men show an inverted CD4/ CD8 T-cell ratio compared to women of the same age [89]. Also, the proliferative and cytokine secretion capacity of $\mathrm{T}$ cells of older men is diminished more so than older women [90].

All these findings could explain at least in part the higher COVID-19 incidence and mortality in elderly men than in elderly women.

\section{COVID-19 in the elderly: clinical presentation and therapeutic challenges}

\section{Clinical characteristics}

Liu et al. [46] analyzed the clinical characteristics of elderly patients with COVID-19 to dissect differences between elderly and younger patients. The most common symptoms in both groups were fever, cough and sputum; concomitant less common symptoms were runny nose, headache, diarrhea. The Pneumonia Severity Index (PSI) score of the elderly group was higher when compared to the young and middle-aged group: the proportion of patients with PSI grade IV and V was significantly higher in the elderly group. Among elderly patients, it should be noted that the percentage of patients complaining of more severe dyspnea and tachypnea was higher in non-survivors, while fever and headache were more common in survivors [2]. Atypical presentation in older adults may include delirium, low-grade hyperpyrexia, and abdominal pain, complicating the diagnostic course [91].

\section{Laboratory findings and CT Imaging}

Routine blood tests are widely used in diagnosing and monitoring the course of COVID-19. In a single-center retrospective study, no significant differences in white blood cell count, neutrophil ratio, procalcitonin, hemoglobin level, platelet, and serum creatinine were observed in the elderly group of patients. However, the proportion of lymphocytes resulted significantly lower in the elderly compared to young and middle-aged groups; conversely, C-reactive protein was significantly higher in older patients [46]. Interestingly, laboratory parameters may potentially screen at-risk patients whose disease burden is not self-limiting. Indeed, the comparison of laboratory findings between the survival and the dead group in elderly patients, based on 4-week follow-up, showed that neutrophils were significantly increased; while the lymphocytes, monocytes, and platelets were decreased among deceased patients. The prothrombin time was significantly prolonged along with serum urea, creatinine, 
D-Dimer, myocardial markers increase which was observed in the dead group [2].

Amongst the aforementioned diagnostic tools, chest imaging represents the cornerstone for detecting lung abnormalities during viral infection [92, 93]. A previous study documented that chest CT scan has higher sensitivity for the diagnosis of COVID-19 than initial reverse-transcription polymerase chain reaction (RT-PCR) [92]. Typical features of COVID-19 CT presentation include bilateral multilobar ground-glass opacification (GGO) with a peripheral or posterior distribution, mainly in the lower lobes [94]. Atypical initial imaging presentation of consolidative opacities superimposed on GGO may be found in a smaller number of cases, mainly in the elderly population. The multiple lobe involvement was more common in the elderly group than in young and middle-aged group [94].

\section{Pharmacological and non-pharmacological scenario}

Comorbid conditions and polypharmacotherapy have major implications in elderly COVID-19 patients resulting in a particularly multifaceted therapeutic management. Careful assessment of biological emunctory activity and drug selection based on relevant side effects should be prompted.

Firstly, anti-retroviral drugs (mainly lopinavir/ritonavir) are associated with gastrointestinal distress such as nausea, diarrhea, and hepatotoxicity. These adverse effects may be exacerbated by combination therapy and liver injury related to COVID-19; so, they should be relatively contraindicated in frail patients with an underlying hepatopathy. Furthermore, a randomized open-label trial of lopinavir-ritonavir treatment in hospitalized patients with severe Covid-19 showed no clinical improvement or impact on mortality, beyond the standard care [95]. Remdesivir is a nucleoside triphosphate analog with antiviral activity against a broad spectrum of human and zoonotic coronavirus, both in cell cultures and mouse models, including SARS-CoV, MERSCoV, and SARS-CoV2 [96]. Effectiveness data from a multicenter cohort study suggest that remdesivir use might be beneficial, as 36 of 53 patients (68\%) showed an improvement in the category of oxygen support after the first dose administration. However, the study was limited by the small number of patients, lack of randomization, and the absence of rigorous inclusion/exclusion criteria. Additionally, $60 \%$ of patients developed side effects, including raised hepatic enzymes, diarrhea, rash, renal impairment, and hypotension [97]. Remdesivir is contraindicated in patients with an estimated glomerular filtration rate below $30 \mathrm{~mL} / \mathrm{min}$. Therefore, the elderly might experience harmful related effects and this should be considered before starting the treatment.

Among treatments experimented during COVID-19 pandemic, chloroquine and hydroxychloroquine have been widely used based on early studies which suggest potential anti-viral activity along with anti-inflammatory effects [98, 99]. These agents are relatively well tolerated, but can cause rare and serious adverse effects $(<10 \%)$, including QTc prolongation, hypoglycemia, neuropsychiatric effects, and retinopathy. Baseline and follow-up electrocardiography are currently recommended especially in critically ill patients and in those taking concomitant QT-interval prolonging agents (e.g., macrolides and fluoroquinolones). However, very recent clinical data from a retrospective multicenter study documented a lack of significant benefit in hospitalized patients treated with hydroxychloroquine alone or in combination with azithromycin [100].

Corticosteroids, especially methylprednisone, have been used to counteract the inflammatory response of COVID19 patients with severe pneumonia and/or ARDS. However, in elderly patients, their benefits may be outweighed by metabolic side effects, which can precipitate pre-existing comorbidities including hypertension, diabetes, risk of bone fractures, psychiatric alterations, and cataract [101]. Interferon nebulized inhalation, used in patients with respiratory symptoms, was reported to induce faster cough relief in elderly patients, and such effect seems to be more relevant when compared to young and middle-aged groups [102].

Tocilizumab, an IL-6 receptor antagonist, has been used in a small series of severe COVID-19 cases. Superimposed infections are the most frequent type of adverse events observed after the administration of Tocilizumab: diabetes, age $\geq 65$ years, a history of previous infections, and corticosteroid use have been associated with increased susceptibility of developing a severe infection [103]. Several clinical trials are currently ongoing (NCT04346355, NCT04331795, NCT04332094, NCT04377659, NCT04335071, NCT04377750, NCT04317092). Advanced age is generally not an exclusion criterion per sè in the aforementioned trials, though patients with advanced liver, heart, or kidney disease are commonly excluded.

Autopsy evidence of higher incidence of deep vein thrombosis (DVT) and pulmonary embolism (PE) in patients with COVID-19 [31, 104] has prompted attention on thromboprophylactic agents-also based on potential anti-inflammatory effects of heparin. However, recent evidence suggests that only patients with sepsis-induced coagulation score $\geq 4$, or with D-dimer levels above $3.0 \mu \mathrm{g} / \mathrm{mL}$ (sixfold of upper limit of normal) might benefit from anticoagulation [105]. Furthermore, based on the evidence that, in COVID-19 patients treated with antiviral drugs, direct oral anticoagulants (DOACs) plasmatic concentration increases up to 6.14 times during the hospitalization, DOACs replacement with alternative parenteral antithrombotic strategies needs to be considered [106].

Another postulated mechanism interfering with SARSCoV-2 infections is based on ACE2 modulation. ACE inhibitors (ACE-Is) and angiotensin receptor blockers (ARBs) 
are commonly used among older adults to treat systemic hypertension, for preventing diabetic nephropathy or hearth remodeling in ischemic heart disease [34]. Early data in rat models suggest that these agents may prompt a possible retrograde feedback mechanism by which ACE2 receptors are upregulated [107, 108]. The possible positive role of ACE-Is or ARBs in limiting ARDS inflammation pathways activated by the virus entry has been postulated [38]. Recent data from a retrospective cohort study support the use of ACEIs/ARBs based on evidence of reduced all-cause mortality. International recommendations, at this time, suggest against ACE-Is or ARBs discontinuation at this stage [109-113].

Immobilization, muscular deconditioning, fatigue, and dyspnea are common among elderly patients hospitalized for COVID-19. Early in-hospital pulmonary rehabilitation should be considered as a minimum of clinical stability is achieved. Prolonged physical activities in home-based settings after patients discharge would be potentially beneficial [114-118]. Finally, despite optimized medical treatment, some patients with end-stage COVID-19 pneumonia progress to irreversible loss of lung function [119]. A report of two successful lung transplantations of critical elderly patients with severe COVID-19 pneumonia was described, though authors do not recommend lung transplantation in patients with positive viral RNA tests [120].

\section{Nursing homes and palliation}

There is growing apprehension regarding elderly living in long-stay residential care homes (LSRCHs), where close contact between residents and the staff might fuel transmission [121]. As of 14th April 2020, 40.2\% of 6773 subjects deceased in LSRCHs showed respiratory symptoms in accordance with an ongoing analysis launched on 1st February 2020 in Italy [122]. Several factors may concur resulting in increased risk for LSRCHs epidemic during the early stages of the SARS-CoV-2 outbreak. First, the ratio of health personnel/residents is generally limited and not adequate to sustain in emergency situations [123]. Second, lack of personal protective equipment, poor swab availability, absence of prompt health care guidelines to minimize the infection spread, lack of available drugs were reported in $82.7 \%$, $46.9 \%, 19.9 \%$, and $10.3 \%$ [124]. Furthermore, the imbalance between the caregiver and the number of residents is further accentuated as nursing staff are missing due to sick leave or mandatory quarantine or due to fear of working without the appropriate personal protective equipment [125]. WHO developed guidelines for patient management in LSRCHs [126]. Main recommendations include: produce a training protocol and nursing management; assure well-defined rules for containing visits and social distancing; provide adequate resources to contain the spread of the infection, in any case, ensure good palliative support therapy if the residents are infected. Particular importance is reserved for the support of health care workers and caregivers, guaranteeing physical, psychological, and mental security to work well, preventing excessive anxiety and worries [127]. To improve the functioning of these structures and ensure a high quality of services, they should have a greater geriatric imprint and be integrated within the basic health vices [128]. However, restrictive measures impact the patient who feels abandoned, frightened, and perhaps not even able to understand the situation or remember the safeguard procedures. This problem affects even more those patients with major cognitive deficits and dementia [129]. It is essential to provide these patients with good psychological support. Isolation at home, or in nursing homes, causes an exceptional change in their habits, and feelings such as fear, anxiety, and loneliness can lead to real depression [130]. Living isolated from daily activities, without the ability to access the most modern telecommunication services, determines an altered perception of reality, a change in the sleep-wake rhythm, risking to flow into forms of real delirium [131]. This situation can also cause trauma, with secondary post-traumatic stress syndrome. All these elements can lead to an acceleration of cognitive decline, with an important risk of suicides [132, 133]. In China, five organizations promptly issued recommendations on how to provide psychological and psychiatric support, with, for example, free counseling services for elderly patients with dementia and their caregivers. This seems to have minimized the impact of the side effects of COVID-19 [129].

The rapid progress of the emergency and the need to treat a large number of patients in ICU in a short period led to rapid exhaustion of the beds, with very long hospital stays. When resources are not sufficient, access to the ICU is not guaranteed for everyone. The Italian Society of Anesthesia Analgesia Intensive Care (SIAARTI) has drawn up the guidelines for managing ICU admissions in a COVID-19 emergency suggesting reduced ICU access to patients with a limited life perspective [134]. The most effective palliative care must be ensured to endure, both physically and psychologically, the end of life, as widely recommended by the World Health Organization [135]. On April 2, 2020, the Italian Palliative Care Society (SICP), the SIAARTI and the Palliative Care Federation (FCP) issued a Position paper 'Palliative Care in Treatment of the sick Covid-19/ Sars-Cov-2 [136]. This document outlines the treatments for those patients who are not candidates for intensive care, in whom the symptoms become unbearable. It is recommended that healthcare institutions include palliative care protocols in COVID-19 care pathways for regional and local palliative care networks. Furthermore, palliative care management should be included in the regional and local Crisis Units for coordinating different health care settings (hospital, home, RSA/RSD and other types of hospitalization). It is a good clinical practice, but above all a deontological and legal duty 
to alleviate the suffering also in this type of patient in the final stages of life [136].

Finally, at this time, there is lack of knowledge about the sequelae which may be prompted by COVID-19 (e.g., interstitial lung disease or chronic thromboembolic pulmonary embolism). Follow-up studies will offer new insights into identifying the long-term consequences of this pandemic.

\section{Conclusions}

Elderly patients are particularly susceptible to adverse clinical outcomes in SARS Cov-2 infection and assessment and treatment is challenging. Based on the current data, an individualized approach should be offered to older adults targeting the beneficial and negative effects of therapeutic decisions. Long-stay residential care homes and hospitals need to urgently design adequate health care plans for elderly patients. Frailty needs to be addressed to provide the most effective therapeutic options in COVID-19. Until more progress in treatment is achieved, it is recommended that the elderly population should remain shielded during COVID-19 outbreaks.

Author contributions $\mathrm{AB}, \mathrm{GC}, \mathrm{FP}, \mathrm{GeM}$ and $\mathrm{RP}$ contributed to conceptualization. FP, GC, AB drew the manuscript outline. FP, GC, KK, GrM, LA, MB, VDA reviewed the literature and wrote the original draft. FP, GC, GeM, RP and AB revised the original draft. All authors have read and approved the final version of the manuscript. FP is the guarantor of the paper. All authors have read and approved the final version of the manuscript.

Funding The authors have no funding.

\section{Compliance with ethical standards}

Conflict of interest The authors have no conflict of interest to declare with the present manuscript.

Ethical approval Not applicable.

Informed consent Not applicable.

\section{References}

1. World Health Organization (2020) Coronavirus disease 2019 (COVID-19) situation report—97. World Health Organization, Geneva

2. Wang L, He W, Yu X et al (2020) Coronavirus disease 2019 in elderly patients: characteristics and prognostic factors based on 4-week follow-up. J Infect. https://doi.org/10.1016/j. jinf.2020.03.019

3. Masters PS (2006) The molecular biology of coronaviruses. Adv Virus Res 66:193-292
4. Kang S, Peng W, Zhu Y et al (2020) Recent progress in understanding 2019 novel coronavirus (SARS-CoV-2) associated with human respiratory disease: detection, mechanisms and treatment. Int J Antimicrob Agents 55(5):105950. https://doi.org/10.1016/j. ijantimicag.2020.105950

5. Gorbalenya AE, Baker SC, Baric RS et al (2020) The species severe acute respiratory syndrome-related coronavirus: classifying 2019-nCoV and naming it SARS-CoV-2. Nat Microbiol 5:536-544

6. Zhou P, Yang X-L, Wang X-G et al (2020) A pneumonia outbreak associated with a new coronavirus of probable bat origin. Nature. https://doi.org/10.1038/s41586-020-2012-7

7. Report S (2020) Novel coronavirus (2019-nCoV) situation report-22. World Health Organization, Geneve

8. World Health Organization (2020) Modes of transmission of virus causing COVID-19: implications for IPC precaution recommendations. World Health Organization, Geneva, pp 10-12

9. Xu Y, Li X, Zhu B et al (2020) Characteristics of pediatric SARS-CoV-2 infection and potential evidence for persistent fecal viral shedding. Nat Med 26:502-505

10. Hindson J (2020) COVID-19: faecal-oral transmission? Nat Rev Gastroenterol Hepatol 17:259

11. Chen N, Zhou M, Dong X et al (2020) Epidemiological and clinical characteristics of 99 cases of 2019 novel coronavirus pneumonia in Wuhan, China: a descriptive study. Lancet (Lond Engl) 395:507-513

12. Zhu N, Zhang D, Wang W et al (2020) A novel coronavirus from patients with pneumonia in China, 2019. N Engl J Med 382:727-733

13. Zhou F, Yu T, Du R et al (2020) Clinical course and risk factors for mortality of adult inpatients with COVID-19 in Wuhan, China: a retrospective cohort study. Lancet 395:1054-1062

14. Nishiura H, Kobayashi T, Suzuki A et al (2020) Estimation of the asymptomatic ratio of novel coronavirus infections (COVID19). Int J Infect Dis IJID Off Publ Int Soc Infect Dis. https://doi. org/10.1016/j.ijid.2020.03.020

15. Libertini G, Corbi G, Cellurale M et al (2019) Age-related dysfunctions: evidence and relationship with some risk factors and protective drugs. Biochemistry (Mosc) 84:1442-1450

16. Lionakis N, Mendrinos D, Sanidas E et al (2012) Hypertension in the elderly. World J Cardiol 4:135-147

17. Suastika K, Dwipayana P, Ratna Saraswati IM et al (2011) Relationship between age and metabolic disorders in the population of Bali. J Clin Gerontol 2:47-52

18. Palmieri L, Andrianou X, Barbariol P et al (2020) Characteristics of SARS-CoV-2 patients dying in Italy report based on available data on April 16th, 2020

19. Moher D, Liberati A, Tetzlaff J et al (2009) Preferred reporting items for systematic reviews and meta-analyses: the PRISMA statement. PLoS Med 6:e1000097

20. Whiteman SC, Bianco A, Knight RA et al (2003) Human rhinovirus selectively modulates membranous and soluble forms of its intercellular adhesion molecule-1 (ICAM-1) receptor to promote epithelial cell infectivity. J Biol Chem 278:11954-11961

21. Bianco A, Sethi SK, Allen JT et al (1998) Th2 cytokines exert a dominant influence on epithelial cell expression of the major group human rhinovirus receptor, ICAM-1. Eur Respir J 12:619-626

22. Sethi SK, Bianco A, Allen JT et al (1997) Interferon-gamma (IFN-gamma) down-regulates the rhinovirus-induced expression of intercellular adhesion molecule-1 (ICAM-1) on human airway epithelial cells. Clin Exp Immunol 110:362-369

23. Bianco A, Whiteman SC, Sethi SK et al (2000) Expression of intercellular adhesion molecule-1 (ICAM-1) in nasal epithelial cells of atopic subjects: a mechanism for increased rhinovirus infection? Clin Exp Immunol 121:339-345 
24. Giannattasio A, Brunese L, Ripabelli G et al (2018) Coinfections with influenza virus and atypical bacteria: Implications for severe outcomes? Clin Respir J 12:366-367

25. Bianco A, Parrella R, Esposito V et al (2011) Severe A(H1N1)associated pneumonia sequential to clamidophila pneumoniae infection in Healthy Subject. Vivo 25:825-828

26. Svartengren M, Falk R, Philipson K (2005) Long-term clearance from small airways decreases with age. Eur Respir J 26:609-615

27. Levitzky MG (1984) Effects of aging on the respiratory system. Physiologist 27:102-107

28. Martin SE, Mathur R, Marshall I et al (1997) The effect of age, sex, obesity and posture on upper airway size. Eur Respir J 10:2087-2090

29. Xu J, Kang Y-A, Park S-K et al (2019) Nasality changes with age in normal Korean-speaking adults. Clin Exp Otorhinolaryngol 12:95-99

30. Mason RJ (2020) Pathogenesis of COVID-19 from a cell biology perspective. Eur Respir J. https://doi.org/10.1183/13993 003.00607-2020

31. Cao W, Li T (2020) COVID-19: towards understanding of pathogenesis. Cell Res. https://doi.org/10.1038/s41422-020-0327-4

32. Wichmann D, Sperhake J-P, Lütgehetmann M et al (2020) Autopsy findings and venous thromboembolism in patients with COVID-19: a prospective cohort study. Ann Intern Med. https:// doi.org/10.7326/M20-2003

33. Bosch BJ, van der Zee R, de Haan CAM et al (2003) The coronavirus spike protein is a class I virus fusion protein: structural and functional characterization of the fusion core complex. J Virol 77:8801-8811

34. Perrotta F, Matera MG, Cazzola M et al (2020) Severe respiratory SARS-CoV2 infection: does ACE2 receptor matter? Respir Med 168:105996

35. Hoffmann M, Kleine-Weber H, Schroeder S et al (2020) SARSCoV-2 cell entry depends on ACE2 and TMPRSS2 and is blocked by a clinically proven protease inhibitor. Cell 181:271280. https://doi.org/10.1016/j.cell.2020.02.052

36. Ou X, Liu Y, Lei X et al (2020) Characterization of spike glycoprotein of SARS-CoV-2 on virus entry and its immune crossreactivity with SARS-CoV. Nat Commun 11:1620

37. Lan J, Ge J, Yu J et al (2020) Structure of the SARS-CoV-2 spike receptor-binding domain bound to the ACE2 receptor. Nature. https://doi.org/10.1038/s41586-020-2180-5

38. Rodrigues Prestes TR, Rocha NP, Miranda AS et al (2017) The anti-inflammatory potential of ACE2/angiotensin-(1-7)/mas receptor axis: evidence from basic and clinical research. Curr Drug Targets 18:1301-1313

39. Gaddam RR, Chambers S, Bhatia M (2014) ACE and ACE2 in inflammation: a tale of two enzymes. Inflamm Allergy Drug Targets 13:224-234

40. Donoghue M, Hsieh F, Baronas E et al (2000) A novel angiotensin-converting enzyme-related carboxypeptidase (ACE2) converts angiotensin I to angiotensin 1-9. Circ Res 87:E1-E9

41. Imai Y, Kuba K, Penninger JM (2008) The discovery of angiotensin-converting enzyme 2 and its role in acute lung injury in mice. Exp Physiol 93:543-548

42. Schouten LRA, Helmerhorst HJF, Wagenaar GTM et al (2016) Age-dependent changes in the pulmonary renin-angiotensin system are associated with severity of lung injury in a model of acute lung injury in rats. Crit Care Med 44:e1226-e1235

43. Xu H, Zhong L, Deng J et al (2020) High expression of ACE2 receptor of 2019-nCoV on the epithelial cells of oral mucosa. Int J Oral Sci 12:1-5

44. AlGhatrif M, Cingolani O, Lakatta EG (2020) The dilemma of coronavirus disease 2019, aging, and cardiovascular disease: insights from cardiovascular aging science. JAMA Cardiol. https ://doi.org/10.1001/jamacardio.2020.1329
45. Ferguson ND, Fan E, Camporota L et al (2012) The Berlin definition of ARDS: an expanded rationale, justification, and supplementary material. Intensive Care Med 38:1573-1582

46. Liu K, Chen Y, Lin R et al (2020) Clinical features of COVID-19 in elderly patients: a comparison with young and middle-aged patients. J Infect. https://doi.org/10.1016/j. jinf.2020.03.005

47. Gattinoni L, Coppola S, Cressoni M et al (2020) Covid-19 does not lead to a "typical" acute respiratory distress syndrome. Am J Respir Crit Care Med. https://doi.org/10.1164/rccm.20200 3-0817LE

48. Tian S, Xiong Y, Liu H et al (2020) Pathological study of the 2019 novel coronavirus disease (COVID-19) through postmortem core biopsies. Mod Pathol. https://doi.org/10.1038/s4137 9-020-0536-x

49. Fox SE, Akmatbekov A, Harbert JL et al (2020) Pulmonary and cardiac pathology in Covid-19: the first autopsy series from New Orleans. Lancet Respir Med. https://doi.org/10.1016/S2213 $-2600(20) 30243-5$

50. Huang C, Wang Y, Li X et al (2020) Clinical features of patients infected with 2019 novel coronavirus in Wuhan, China. Lancet 395:497-506

51. Clark IA, Vissel B (2017) The meteorology of cytokine storms, and the clinical usefulness of this knowledge. Semin Immunopathol 39:505-516

52. Mehta P, McAuley DF, Brown M et al (2020) COVID-19: consider cytokine storm syndromes and immunosuppression. Lancet 6736:19-20

53. Daniele A, De Rosa A, Nigro E et al (2012) Adiponectin oligomerization state and adiponectin receptors airway expression in chronic obstructive pulmonary disease. Int J Biochem Cell Biol 44:563-569

54. Di Zazzo E, Polito R, Bartollino S et al (2019) Adiponectin as link factor between adipose tissue and cancer. Int J Mol Sci. https ://doi.org/10.3390/ijms20040839

55. Nigro E, Stiuso P, Matera MG et al (2019) The anti-proliferative effects of adiponectin on human lung adenocarcinoma A549cells and oxidative stress involvement. Pulm Pharmacol Ther. https:// doi.org/10.1016/j.pupt.2019.01.004

56. Perrotta F, Nigro E, Mollica M et al (2019) Pulmonary hypertension and obesity: focus on adiponectin. Int J Mol Sci. https://doi. org/10.3390/ijms20040912

57. Perrotta F, Rocco D, Vitiello F et al (2019) Immune checkpoint blockade for advanced NSCLC: a new landscape for elderly patients. Int J Mol Sci. https://doi.org/10.3390/ijms20092258

58. Aw D, Silva AB, Palmer DB (2007) Immunosenescence: emerging challenges for an ageing population. Immunology 120:435-446

59. Longobardi L (2016) Bronchial asthma in the elderly patient. J Gerontol Geriatr 64:55-65

60. Mollica M, Nicolai A, Maffucci R et al (2018) Obstructive sleep apnea and cardiovascular risks in the elderly population. Gerontol Geriatr 66:149-155

61. Ho JC, Chan KN, Hu WH et al (2001) The effect of aging on nasal mucociliary clearance, beat frequency, and ultrastructure of respiratory cilia. Am J Respir Crit Care Med 163:983-988

62. Aiello A, Farzaneh F, Candore G et al (2019) Immunosenescence and its hallmarks: how to oppose aging strategically? A review of potential options for therapeutic intervention. Front Immunol 10:2247

63. Cattaneo F, Guerra G, Parisi M et al (2015) Expression of formyl-peptide receptors in human lung carcinoma. Anticancer Res 35:2769-2774

64. Pinti M, Appay V, Campisi J et al (2016) Aging of the immune system: focus on inflammation and vaccination. Eur J Immunol 46:2286-2301 
65. Bomfim GF, Echem C, Martins CB et al (2015) Toll-like receptor 4 inhibition reduces vascular inflammation in spontaneously hypertensive rats. Life Sci 122:1-7

66. Harrison DG, Guzik TJ, Lob HE et al (2011) Inflammation, immunity, and hypertension. Hypertens (Dallas, Tex 1979) 57:132-140

67. Guaraldi G, Zona S, Silva AR et al (2019) The dynamic association between Frailty, CD4 and CD4/CD8 ratio in people aging with HIV. PLoS One 14:e0212283

68. Corbi G, Cacciatore F, Komici K et al (2019) Inter-relationships between Gender, Frailty and 10-Year Survival in Older Italian Adults: an observational longitudinal study. Sci Rep 9:18416

69. Colonna-Romano G, Bulati M, Aquino A et al (2009) A double-negative (IgD-CD27-) B cell population is increased in the peripheral blood of elderly people. Mech Ageing Dev 130:681-690

70. Panatto D, Signori A, Lai PL et al (2018) Heterogeneous estimates of influenza virus types A and B in the elderly: results of a meta-regression analysis. Influenza Other Respir Viruses 12:533-543

71. European Centre for Disease Prevention and Control (2018) European Centre for Disease Prevention and Control. Seasonal influenza, 2017-2018. ECDC. Annual epidemiological report for 2017. ECDC, Stockholm

72. Bader MS, McKinsey DS (2005) Viral infections in the elderly. The challenges of managing herpes zoster, influenza, and RSV. Postgrad Med 118:45-48, 51-54

73. Weinberger B (2018) Vaccines for the elderly: current use and future challenges. Immun Ageing 15:3

74. Bianco A, Perrotta F, Barra G et al (2019) Prognostic factors and biomarkers of responses to immune checkpoint inhibitors in lung cancer. Int J Mol Sci. https://doi.org/10.3390/ijms20194931

75. Karlberg J, Chong DSY, Lai WYY (2004) Do men have a higher case fatality rate of severe acute respiratory syndrome than women do? Am J Epidemiol 159:229-231

76. Leong H-N, Earnest A, Lim H-H et al (2006) SARS in Singapore-predictors of disease severity. Ann Acad Med Singap 35:326-331

77. Alghamdi IG, Hussain II, Almalki SS et al (2014) The pattern of Middle East respiratory syndrome coronavirus in Saudi Arabia: a descriptive epidemiological analysis of data from the Saudi Ministry of Health. Int J Gen Med 7:417-423

78. Conti P, Younes A (2020) Coronavirus COV-19/SARS-CoV-2 affects women less than men: clinical response to viral infection. J Biol Regul Homeost Agents. https://doi.org/10.23812/EditorialConti-3

79. Xie X, Chen J, Wang X et al (2006) Age- and gender-related difference of ACE2 expression in rat lung. Life Sci 78:2166-2171

80. Zill P, Baghai TC, Schule C et al (2012) DNA methylation analysis of the angiotensin converting enzyme (ACE) gene in major depression. PLoS One 7:e40479

81. Holmes LJ, Lim A, Comeaux CR et al (2019) DNA methylation of candidate genes (ACE II, IFN-gamma, AGTR 1, CKG, ADD1, SCNN1B and TLR2) in essential hypertension: a systematic review and quantitative evidence synthesis. Int J Environ Res Public Health. https://doi.org/10.3390/ijerph16234829

82. Tipnis SR, Hooper NM, Hyde R et al (2000) A human homolog of angiotensin-converting enzyme. Cloning and functional expression as a captopril-insensitive carboxypeptidase. J Biol Chem 275:33238-33243

83. Jin J-M, Bai P, He W et al (2020) Gender differences in patients with COVID-19: focus on severity and mortality. Front Public Heal 8:152

84. Fan R, Mao S-Q, Gu T-L et al (2017) Preliminary analysis of the association between methylation of the ACE2 promoter and essential hypertension. Mol Med Rep 15:3905-3911
85. Pal S, Tyler JK (2016) Epigenetics and aging. Sci Adv 2:e1600584

86. Li S, Lund JB, Christensen K et al (2020) Exploratory analysis of age and sex dependent DNA methylation patterns on the X-chromosome in whole blood samples. Genome Med 12:39

87. Klein SL, Morgan R (2020) The impact of sex and gender on immunotherapy outcomes. Biol Sex Differ 11:24

88. Channappanavar R, Fett C, Mack M et al (2017) Sex-based differences in susceptibility to severe acute respiratory syndrome coronavirus infection. J Immunol 198:4046-4053

89. Gubbels Bupp MR (2015) Sex, the aging immune system, and chronic disease. Cell Immunol 294:102-110

90. Strindhall J, Skog M, Ernerudh J et al (2013) The inverted CD4/ CD8 ratio and associated parameters in 66-year-old individuals: the Swedish HEXA immune study. Age (Dordr) 35:985-991

91. Goetzl EJ, Huang M-C, Kon J et al (2010) Gender specificity of altered human immune cytokine profiles in aging. FASEB J Off Publ Fed Am Soc Exp Biol 24:3580-3589

92. Tay HS, Harwood R (2020) Atypical presentation of COVID-19 in a frail older person. Age Ageing. https://doi.org/10.1093/agein g/afaa068

93. Lee EYP, Ng M-Y, Khong P-L (2020) COVID-19 pneumonia: what has CT taught us? Lancet Infect Dis 20:384-385

94. Rinaldi L, Milione S, Fascione MC et al (2019) Relevance of lung ultrasound in the diagnostic algorithm of respiratory diseases in a real-life setting: a multicentre prospective study. Respirology. https://doi.org/10.1111/resp.13659

95. Salehi S, Abedi A, Balakrishnan S et al (2020) Coronavirus disease 2019 (COVID-19): a systematic review of imaging findings in 919 patients. AJR Am J Roentgenol. https://doi.org/10.2214/ AJR.20.23034

96. Cao B, Wang Y, Wen D et al (2020) A trial of lopinavir-ritonavir in adults hospitalized with severe Covid-19. N Engl J Med. https ://doi.org/10.1056/NEJMoa2001282

97. Li Z, Wang X, Cao D et al (2020) Rapid review for the anticoronavirus effect of remdesivir. Drug Discov Ther 14:73-76

98. Grein J, Ohmagari N, Shin D et al (2020) Compassionate use of remdesivir for patients with severe Covid-19. N Engl J Med. https://doi.org/10.1056/NEJMoa2007016

99. Sanders JM, Monogue ML, Jodlowski TZ et al (2020) Pharmacologic treatments for coronavirus disease 2019 (COVID-19) a review. JAMA. https://doi.org/10.1001/jama.2020.6019

100. Gautret P, Lagier J-C, Parola P et al (2020) Hydroxychloroquine and azithromycin as a treatment of COVID-19: results of an open-label non-randomized clinical trial. Int J Antimicrob Agents. https://doi.org/10.1016/j.ijantimicag.2020.105949

101. Rosenberg ES, Dufort EM, Udo T et al (2020) Association of treatment with hydroxychloroquine or azithromycin with in-hospital mortality in patients with COVID-19 in New York state. JAMA. https://doi.org/10.1001/jama.2020.8630

102. Dhaou BBB, Boussema F, Aydi Z et al (2012) Corticoid-associated complications in elderly. Tunis Med 90(11):774-777

103. Zhou Q, Wei X-S, Xiang X et al (2020) Interferona2b treatment for COVID-19. medRxiv. https://doi. org/10.1101/2020.04.06.20042580

104. Jones G, Ding C (2010) Tocilizumab: a review of its safety and efficacy in rheumatoid arthritis. Clin Med Insights Arthritis Musculoskelet Disord 3:81-89

105. Tian S, Hu W, Niu L et al (2020) Pulmonary pathology of earlyphase 2019 novel coronavirus (COVID-19) pneumonia in two patients with lung cancer. J Thorac Oncol Off Publ Int Assoc Study Lung Cancer. https://doi.org/10.1016/j.jtho.2020.02.010

106. Boccia M, Aronne L, Celia B et al (2020) COVID-19 and coagulative axis : review of emerging aspects in a novel disease. Monaldi Arch Chest Dis. https://doi.org/10.4081/monal di. 2020.1300 
107. Testa S, Prandoni P, Paoletti O et al (2020) Direct oral anticoagulant plasma levels striking increase in severe COVID-19 respiratory syndrome patients treated with antiviral agents: the Cremona experience. J Thromb Haemost 18(6):1320-1323. https ://doi.org/10.1111/jth.14871

108. Ishiyama Y, Gallagher PE, Averill DB et al (2004) Upregulation of angiotensin-converting enzyme 2 after myocardial infarction by blockade of angiotensin II receptors. Hypertens (Dallas, Tex 1979) 43:970-976

109. Yuan Y-M, Luo L, Guo Z et al (2015) Activation of renin-angiotensin-aldosterone system (RAAS) in the lung of smokinginduced pulmonary arterial hypertension (PAH) rats. J Renin Angiotensin Aldosterone Syst 16:249-253

110. Rico-Mesa JS, White A, Anderson AS (2020) Outcomes in Patients with COVID-19 Infection Taking ACEI/ARB. Curr Cardiol Rep 22:20-23

111. European Society of Cardiology (ESC). Position Statement of the ESC Council on Hypertension on ACE-Inhibitors and Angiotensin Receptor Blockers (2020). https://www.escardio.org/Counc ils/Council-on-Hypertension-(CHT)/News/position-statementof-the-esc-council-on-hypertension-on-ace-inhibitors-and-ang. Accessed 18 Mar 2020

112. European Society of Hypertension (2020) Statement of the European Society of Hypertension (ESH) on hypertension, Renin Angiotensin System blockers and COVID-19 March 19th 2020

113. Trifirò G, Crisafulli $S$, Andò $G$ et al (2020) Should patients receiving ACE inhibitors or angiotensin receptor blockers be switched to other antihypertensive drugs to prevent or improve prognosis of novel coronavirus disease 2019 (COVID-19)? Drug Saf. https://doi.org/10.1007/s40264-020-00935-2

114. International Society of Hypertension (2020) A statement from the International Society of Hypertension on COVID-19. Available at https://ishworld.com/news/a/A-statement-from-the-Inter national-Society-of-Hypertension-on-COVID-19. Accessed 21 May 2020

115. Vitacca M, Carone M, Clini EM et al (2020) Joint statement on the role of respiratory rehabilitation in the COVID-19 crisis: the Italian position paper. Respiration. https://doi.org/10.1159/00050 8399

116. Salvi R, Meoli I, Cennamo A et al (2016) Preoperative highintensity training in frail old patients undergoing pulmonary resection for NSCLC. Open Med. https://doi.org/10.1515/ med-2016-0079

117. Rispoli M, Salvi R, Cennamo A et al (2020) Effectiveness of home-based preoperative pulmonary rehabilitation in COPD patients undergoing lung cancer resection. Tumori. https://doi. org/10.1177/0300891619900808

118. Perrotta F, Cennamo A, Cerqua FS et al (2019) Effects of a highintensity pulmonary rehabilitation program on the minute ventilation/carbon dioxide output slope during exercise in a cohort of patients with COPD undergoing lung resection for non-small cell lung cancer. Jornal Brasileiro de Pneumologia 45:e20180132

119. Lazzeri M, Lanza A, Bellini R et al (2020) Respiratory physiotherapy in patients with COVID-19 infection in acute setting: a Position Paper of the Italian Association of Respiratory Physiotherapists (ARIR). Monaldi Arch Chest Dis. https://doi. org/10.4081/monaldi.2020.1285

120. Wu C, Chen X, Cai Y et al (2020) Risk factors associated with acute respiratory distress syndrome and death in patients with coronavirus disease 2019 pneumonia in Wuhan. JAMA Intern Med, China. https://doi.org/10.1001/jamainternmed.2020.0994

121. Han W, Zhu M, Chen J et al (2020) Lung transplantation for elderly patients with end-stage COVID-19 Pneumonia. Ann Surg. https://doi.org/10.1097/SLA.0000000000003955

122. Mcmichael TM, Clark S, Pogosjans S et al (2020) COVID-19 in a long-term care facility-king county, Washington, February 27-March 9, 2020. MMWR Morb Mortal Wkly Rep. https://doi. org/10.15585/mmwr.mm6912e1

123. Ancidoni A, Bacigalupo I, Bellomo G et al (2020) A survey on COVID-19 infection in long-stay residential care homes-update 14 April 2020 (Istituto Superiore di Sanità)

124. Huhtinen E, Quinn E, Hess I et al (2019) Understanding barriers to effective management of influenza outbreaks by residential aged care facilities. Australas J Ageing 38:60-63

125. Ancidoni A, Bacigalupo I, Bellomo G et al (2020) Survey nazionale sul contagio COVID-19 nelle strutture residenziali e sociosanitarie PRIMO REPORT, pp 1-24

126. Fallon A, Dukelow T, Kennelly SP et al (2020) COVID-19 in nursing homes. QJM. https://doi.org/10.1093/qjmed/hcaa136

127. World Health Organization (2020) Infection prevention and control guidance for long-term care facilities in the context of COVID-19: interim guidance, 21 March 2020. World Health Organization, Geneva

128. Emergency PH, Concern I, Health M et al (2020) Mental health and psychosocial considerations during COVID-19 outbreak. World Heal Organ, pp 1-6

129. Briggs R, Holmerová I, Martin FC et al (2015) Towards standards of medical care for physicians in nursing homes. Eur Geriatr Med 6:401-403

130. Wang H, Li T, Barbarino P et al (2020) Dementia care during COVID-19. Lancet (Lond Engl) 395:1190-1191

131. Byers AL, Yaffe K (2011) Depression and risk of developing dementia. Nat Rev Neurol 7:323-331

132. Ford $\mathrm{AH}$ (2016) Preventing delirium in dementia: managing risk factors. Maturitas 92:35-40

133. Alphs L, Brashear HR, Chappell P et al (2016) Considerations for the assessment of suicidal ideation and behavior in older adults with cognitive decline and dementia. Alzheimer's Dement (NY N Y) 2:48-59

134. Vergano M, Bertolini G, Giannini A et al (2020) Raccomandazioni di etica clinica per l'ammissione a trattamenti intensivi e per la loro sospensione, in condizioni eccezionali di squilibrio tra necessità e risorse disponibili. Recenti Progressi in Medicina 111:207-211

135. World Health Organization (2018) Integrating palliative care and symptom relief into responses to humanitarian emergencies and crises: a WHO guide. World Health Organization, Geneva

136. Nacoti M, Ciocca A, Giupponi A et al (2020) At the epicenter of the Covid-19 pandemic and humanitarian crises in Italy: changing perspectives on preparation and mitigation. Catal Non-issue content 1:1-5

Publisher's Note Springer Nature remains neutral with regard to jurisdictional claims in published maps and institutional affiliations. 